\title{
Efficacy and safety of the peripheral kappa agonist fedotozine versus placebo in the treatment of functional dyspepsia
}

\author{
N W Read, J L Abitbol, K D Bardhan, P J Whorwell, B Fraitag
}

\begin{abstract}
Background-Peripheral kappa receptor agonists may provide a new therapeutic approach for the treatment of functional dyspepsia.

Aims-To evaluate, in a large multicentre trial, the use of the kappa receptor agonist fedotozine to improve symptoms associated with functional dyspepsia.

Methods-Two or more of the following persistent symptoms were required for inclusion: epigastric pain, early satiety, epigastric fullness or distension, nausea, vomiting, and a feeling of slow digestion. On completing a two week placebo washout, 271 patients were randomised into two groups to receive $30 \mathrm{mg}$ fedotozine three times daily or placebo for six weeks under double blind conditions.

Results-The improvement in the overall intensity of dyspeptic symptoms (main efficacy criterion) was significantly more pronounced in the fedotozine group $(p=0.002)$ compared with placebo, as was epigastric pain $(p=0.004)$ and nausea $(p=0.01)$; the improvement in postprandial fullness was nearly significant $(p=0.052)$. Inability to finish a meal and slow digestion were unaffected. The patient global score, the average of the five individual symptoms, was notably ameliorated with fedotozine $(p=0.021)$. The safety of fedotozine was excellent.

Conclusions-Fedotozine at $30 \mathrm{mg}$ three times daily is safe and more effective than placebo for the relief of key symptoms associated with functional dyspepsia. (Gut 1997; 41: 664-668)
\end{abstract}

Institut de Recherche Jouveinal, Fresnes, France

J L Abitbol

B Fraitag

Rotherham District General Hospital, Rotherham, UK

K D Bardhan

Department of Medicine, University Hospital of South Manchester, Manchester, UK P J Whorwell

Correspondence to: Professor N W Read.

Accepted for publication 12 May 1997

Keywords: fedotozine; functional dyspepsia; kappa receptor agonist

Functional or idiopathic dyspepsia is a commonly occurring chronic digestive disorder affecting $20-40 \%$ of the general population. ${ }^{12}$ This condition is characterised by a recurring, variable cluster of upper abdominal symptoms associated with food intake for which no evidence of organic disease can be found. Like other functional disorders of the gastrointestinal system such as irritable bowel syndrome and gastro-oesophageal reflux, our understanding of the pathophysiological mechanism(s) underlying this condition remains elusive. ${ }^{3}$ Motor, neurohumoral, and sensory abnormalities in both the stomach ${ }^{4-7}$ and small bowel $^{4-9}$ have been demonstrated in some patients with functional dyspepsia, but attempts to classify patients into dyspepsia subgroups based on predominating symptoms linked to such disturbances (dysmotility-like, ulcer-like, reflux-like dyspepsia) do not seem helpful: many patients have symptoms which clearly occupy more than one category. ${ }^{2}$ Moreover, about one third of patients with functional dyspepsia also have symptoms associated with irritable bowel syndrome. ${ }^{210}$ This may explain why the response to drug treatment of dyspepsia based on a symptom oriented classification may be too narrow an approach.

Fedotozine (Institut de Recherche Jouveinal, Fresnes, France) provides a new alternative to the conventional management of functional dyspepsia. This compound acts on the kappa receptors located on afferent neurones in the gut wall, where it is able to modify both sensory and motor responses to stimuli. ${ }^{11-15}$ Physiological investigations have shown that fedotozine inhibits the gastrointestinal effects of stress in $\operatorname{dogs}^{14}$ and raises the threshold of discomfort to gastric distension in healthy subjects. ${ }^{15} \mathrm{~A}$ recent double blind, placebo controlled, dose ranging study in 146 patients showed a significant effect of fedotozine on dyspeptic symptoms at $30 \mathrm{mg}$ and $70 \mathrm{mg}$ thrice daily doses. ${ }^{16}$ The aim of this study was to evaluate and reconfirm the efficacy and safety of fedotozine $30 \mathrm{mg}$ three times daily for six weeks in the treatment of functional dyspepsia in a large multicentre trial.

\section{Patients and Methods}

PATIENT RECRUITMENT AND STUDY DESIGN
In this double blind, randomised, placebo controlled trial, a total of 333 patients (261 outpa$21.6 \%$ ) with functional dyspepsia were initially selected from 25 centres in the UK and Ireland. All volunteers were required to give their informed written consent before entering the study, the protocol of which was approved by the Ethics Committee of each investigational centre as well as by the Pinewood Independent Ethics Committee (Bagshot, Surrey, UK). The main inclusion criterion was the presence of two or more of the following dyspeptic symptoms at least three times per week: inability to finish a normal meal, feeling of postprandial fullness and/or distension in the epigastric region, nausea and/or vomiting associated with eating, feeling of "slow digestion" tients, $78.4 \% ; 72$ primary care patients, 
(an uncomfortable feeling of food in the stomach) persisting beyond the second postprandial hour, and epigastric pain. The symptoms were primarily postprandial, had persisted for at least three months, and were the main reason for the medical consultation. In order to exclude underlying organic disease, upper gastrointestinal endoscopy was performed within the preceding month, and a hepatobiliary ultrasonography within the previous year. Otherwise, the physical examination and routine laboratory examinations were normal. Patients who had undergone digestive surgery, those who were habitual consumers of more than five units of alcohol per day, and those taking corticosteroids, neuroleptics, or any other pharmacological agent likely to affect the gastrointestinal tract (antiulcer drugs or gastric protective agents such as antacids or $\mathrm{H}_{2}$ antagonists) were not included in the study. Finally, persons suffering from another chronic illness were excluded from the trial, as were pregnant women and nursing mothers.

During a one to two week single blind run in phase, all the recruited patients received a placebo tablet three times a day. This period permitted a washout of any previous dyspepsia treatment, a definitive assessment of the patient's dyspeptic symptoms profile, and an appraisal of potential compliance with treatment and his/her ability to perform the self assessments required to evaluate product efficacy. By the end of the run in period, 271 patients complied with the selection criteria. They were then randomised into one of two parallel groups to receive identical tablets of placebo or $30 \mathrm{mg}$ fedotozine at the inclusion visit (V0), and instructed to take them three times daily before each principal meal for six weeks.

\section{ASSESSMENTS}

The main efficacy criterion was the patient self assessment of overall symptom intensity as recorded each evening on a diary card according to the following scale: 0 , zero intensity; 1 , slight intensity with symptoms present but not causing discomfort; 2, moderate intensity, symptoms causing discomfort without disturbing daily activities; 3 , severe intensity whereby symptoms disturb daily activities; 4 , very severe activity such that symptoms cause important disturbances in daily activities and/or require rest. Secondary efficacy criteria included various patient and investigator evaluations. $\mathrm{Pa}-$ tients rated changes in their individual dyspeptic symptoms using the $0-4$ intensity scale described above. They also provided an overall assessment of the therapeutic result at an intermediate patient visit (V1) scheduled after three weeks, and at the final visit (V2) at six weeks. The five grade scale used for this global evaluation was as follows: 0, total disappearance of symptoms; 1, very marked improvement; 2, slight improvement; 3 , no change; 4 , worsening of symptoms.

The investigators evaluated the intensity (same as the patient five grade intensity scale) and frequency (four grade scale: 0 , no symptoms; 1 , low frequency, one to three weekly episodes; 2, moderate frequency, four to six weekly episodes; 3, high frequency; seven or more weekly episodes) of individual dyspeptic symptoms at the three patient visits, judged overall efficacy at V1 and V2 according to the same five grade global evaluation scale used by the patients, and assessed changes in the "main symptoms" (at V1 and V2) which had initially been reported by the patient at the inclusion visit to be the most disabling (using the global evaluation scale).

Physical examinations were carried out at the preinclusion visit, the end of the placebo run in, week 3 , and week 6 , while laboratory tests were performed before inclusion and at the end of the treatment period. Overall safety was also assessed by the patient and investigator at the final visit as being excellent, good, fair, or bad. Adverse events based either on spontaneous complaints or elicited by standardised questioning were recorded at each visit. The patients were qualitatively questioned (yes/no) by the investigators for the presence of associated gastro-oesophageal reflux or irritable bowel syndrome. Finally, a histopathological search for Helicobacter pylori status was carried out in a subset of the study population by means of antral biopsies during the required endoscopic examination.

\section{STATISTICAL ANALYSIS}

At the time the study protocol was prepared, there was no information about the variance of the primary efficacy criterion. The minimum sample size was therefore based on an estimate of the percentage of responders with fedotozine $(75 \%)$ and placebo $(55 \%)$. In order to show a difference between groups with a significance level of $\alpha=0.05$, and with a power $(1-\beta)=0.90$, it was then computed that the minimum sample size would be 117 per treatment group.

Initial demographic characteristics and baseline values were tabulated at V0 for each treatment group to exclude any significant intergroup differences. Student's $t$ test was used to compare baseline values of the efficacy parameters between groups. The mean of the daily overall intensity of symptoms during the six weeks of active treatment was taken as the measure of the overall intensity of dyspeptic symptoms. Analysis of covariance with the baseline inclusion value as covariant was used to test intergroup differences in the "intention to treat" cohort (all patients randomised at V0). The mean values of the investigator global score were analysed in a similar manner. The main efficacy criterion and quantitative secondary criteria were also subjected to repeated measurements analysis (one week as unit of measure) to ascertain whether the time profile of response was identical in both treatment groups. Qualitative secondary efficacy criteria were generally analysed using $\chi^{2}$ tests which were two sided with a significance level of $\alpha=0.05$. Finally, additional statistical analyses were performed on three selective subgroups of interest: dyspeptic patients with symptoms suggesting gastro-oesophageal reflux or irritable bowel syndrome, and an efficacy analysis according to $H$ pylori status. 
TABLE 1 Characteristics of patients at entry

\begin{tabular}{lll}
\hline & Placebo & Fedotozine \\
\hline No. of patients & 131 & 140 \\
Sex (M:F) & $66: 65$ & $66: 74$ \\
Age (years) & $41.0(13.6)$ & $42.8(14.4)$ \\
$\quad$ Mean (SD) & $18-74$ & $18-75$ \\
$\quad$ Range & $72.4(12.9)$ & $70.0(13.5$ \\
Weight (kg) & $1.5(0.7)$ & $1.6(0.7)$ \\
Baseline self evaluation score & $1.2(0.8)$ & $1.3(0.8)$ \\
$\quad$ Overall intensity & $0.7(0.8)$ & $0.8(0.8)$ \\
Epigastric pain & $0.6(0.8)$ & $0.7(0.8)$ \\
Inability to finish meal & $1.2(0.9)$ & $1.2(0.8)$ \\
$\quad$ Nausea & $1.4(0.8)$ & $1.4(0.8)$ \\
Slow digestion & $1.0(0.6)$ & $1.1(0.6)$ \\
Sensation of fullness & $67.2 \%$ & $62.9 \%$ \\
$\quad$ Global score & $74.8 \%$ & $71.4 \%$ \\
Associated symptoms & & \\
$\quad$ Oesophageal reflux & &
\end{tabular}

Results are expressed as mean (SD).

\section{Results}

DEMOGRAPHICS AND BASELINE CHARACTERISTICS During the run in period, the overall symptom intensity was rated as zero, slight, moderate, severe, and very severe on $13.7 \%, 37.3 \%$, $35.3 \%, 11.7 \%$, and $2 \%$ of days, respectively. The most frequent individual symptoms were fullness, slow digestion, and epigastric pain, respectively reported on $78 \%, 70.2 \%$, and $66.1 \%$ of pretreatment days. Among the randomised patients, most $(88.6 \%)$ complained of permanent symptoms of chronic dyspepsia (mean duration 55.1 weeks), with acute periods of exacerbation in $51.7 \%$ of cases lasting an average of 6.3 weeks. Overall in the "intention to treat" cohort, the symptom most often considered as "main" by the patients was epigastric pain $(42.4 \%)$ followed by the sensation of fullness $(32.1 \%)$. No significant differences emerged between treatment groups for the above mentioned parameters.

Table 1 summarises characteristics of the patients entering the six week active part of the trial. Both treatment groups were comparable for demographic and physical parameters, basic illness, and dyspeptic symptoms.

Of the 271 patients randomised at V0, 67 $(24.7 \%)$ were withdrawn before the normal end of the study (34 placebo and 33 fedotozine patients). Treatment related causes (treatment failure or adverse effects) led to 37 premature withdrawals $(55.2 \% ; 15$ placebo and 22 fedotozine patients).

\section{EFFICACY}

After six weeks of treatment under double blind conditions, the improvement in the overall intensity of dyspeptic symptoms (main criterion) was significantly greater in the fedotozine group than among placebo recipients (treatment effect $0.180 ; 95 \%$ confidence intervals 0.07 to $0.29 ; \mathrm{p}=0.002$ ). This reflected a decrease in the overall intensity of dyspeptic symptoms from $1.5(0.7)$ (mean baseline) to $1.2(0.8)$ (six week mean) in the placebo group, and from $1.6(0.7)$ to $1.1(0.7)$ in patients on fedotozine (table 2). As seen in fig 1, repeated measurements analysis showed a significant difference in the time profile of response for the overall intensity of dyspeptic symptoms $(\mathrm{p}=0.002)$.
Table 2 presents the changes in secondary efficacy criteria derived from the patient self assessments. Intergroup differences were significantly in favour of fedotozine for amelioration of epigastric pain $(p=0.004)$ and nausea $(\mathrm{p}=0.01)$; the difference for the sensation of fullness was at the borderline of significance $(\mathrm{p}=0.052)$. The patient global score, the average of the five individual symptoms, was also significantly improved in the fedotozine group $(\mathrm{p}=0.021)$.

Of the "main symptoms", significant improvements were reported with fedotozine for the sensation of fullness $(86.1 \%$ versus $55.6 \%$, $\mathrm{p}=0.046$ ). Figure 2 shows the changes in the mean number of days per week during which patients experienced their most severe dyspeptic symptoms. When symptom intensity is expressed as either very severe/severe, moderate, or slight/nil, fedotozine improved the frequency of occurrence of symptom intensity at approximately double the rate of placebo by the end of the trial. The frequency of slight/pain free days per week increased by $78 \%$, versus $33 \%$ for placebo. In contrast with patient scored results, efficacy assessments by the investigators failed to indicate a significant difference between groups for the main and the secondary efficacy criteria.

Subgroup analyses of dyspeptic patients classified by investigators as having associated gastro-oesophageal reflux failed to reveal intergroup differences for primary or secondary efficacy parameters with one exception: a notably better score for fedotozine for nausea $(p=0.033)$. By contrast, in patients with associated irritable bowel symptoms $(n=198)$, a significant difference in favour of fedotozine emerged for the overall intensity of dyspeptic symptoms $(p=0.008)$. Secondary efficacy parameters in this subgroup paralleled those seen in the entire randomised population, but intergroup differences were situated at the borderline of significance due to the smaller sample size (pain, $p=0.052$; slow digestion, $p=0.055$; global score, $\mathrm{p}=0.069)$. Antral biopsy specimens were available for 133 randomised patients $(49 \%), 61$ in the fedotozine group ( $44 \%$ of group), and 72 in the placebo group ( $55 \%$ of group). From the available biopsy specimens, 56 were negative for $H$ pylori among placebo patients $(76 \%)$, compared with 30 $(49 \%)$ from fedotozine patients. In the

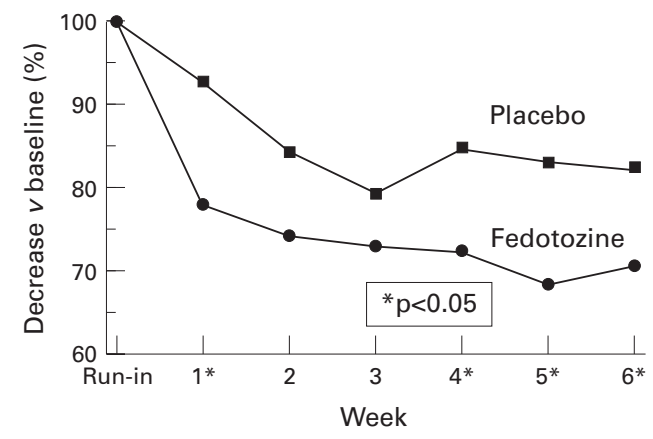

Figure 1: Changes in overall intensity of dyspeptic symptoms during six weeks' treatment with placebo or $30 \mathrm{mg}$ fedotozine as assessed by repeated measurements analysis. 
TABLE 2 Changes in intensity of dyspeptic symptoms as assessed by "intention to treat" patient cohort

\begin{tabular}{|c|c|c|c|c|}
\hline Symptom & Placebo & Fedotozine & Treatment effect $(95 \%$ CI) & $p$ Value \\
\hline \multicolumn{5}{|l|}{ Overall intensity } \\
\hline Inclusion & $1.48(0.68)$ & $1.58(0.68)$ & $0.09-0.16$ & 0.261 \\
\hline Six weekly mean & $1.24(0.78)$ & $1.14(0.71)$ & $-0.18-0.11$ & 0.002 \\
\hline \multicolumn{5}{|l|}{ Epigastric pain } \\
\hline Inclusion & $1.20(0.83)$ & $1.25(0.84)$ & $0.05-0.20$ & 0.638 \\
\hline Six weekly mean & $1.00(0.86)$ & $0.87(0.81)$ & $-0.18-0.12$ & 0.004 \\
\hline \multicolumn{5}{|c|}{ Inability to finish meal } \\
\hline Inclusion & $0.71(0.80)$ & $0.84(0.80)$ & $0.13-0.19$ & 0.171 \\
\hline Six weekly mean & $0.59(0.73)$ & $0.66(0.76)$ & $-0.03-0.10$ & 0.592 \\
\hline \multicolumn{5}{|l|}{ Nausea } \\
\hline Inclusion & $0.62(0.81)$ & $0.73(0.76)$ & $0.11-0.19$ & 0.238 \\
\hline Six weekly mean & $0.56(0.74)$ & $0.52(0.71)$ & $-0.13-0.10$ & 0.010 \\
\hline \multicolumn{5}{|l|}{ Slow digestion } \\
\hline Inclusion & $1.20(0.80)$ & $1.17(0.86)$ & $0.02-0.20$ & 0.836 \\
\hline Six weekly mean & $0.96(0.77)$ & $0.86(0.74)$ & $-0.08-0.12$ & 0.157 \\
\hline \multicolumn{5}{|l|}{ Sensation of fullness } \\
\hline Inclusion & $1.38(0.83)$ & $1.42(0.75)$ & $0.04-0.19$ & 0.643 \\
\hline Six weekly mean & $1.07(0.84)$ & $0.98(0.75)$ & $-0.12-0.12$ & 0.052 \\
\hline \multicolumn{5}{|l|}{ Global score } \\
\hline Inclusion & $1.02(0.62)$ & $1.08(0.62)$ & $0.06-0.15$ & 0.433 \\
\hline Six weekly mean & $0.84(0.63)$ & $0.78(0.62)$ & $-0.10-0.09$ & 0.021 \\
\hline
\end{tabular}

Results are expressed as mean (SD). CI, confidence interval.

subgroup of patients for whom antral biopsy specimens were available, $H$ pylori status had no effect on the outcome of treatment. Finally, there were no differences in the responses to treatment between outpatients and primary care patients.

SAFETY

The safety analysis included 262 of the 271 patients who entered the active phase of the trial: eight placebo and one fedotozine patient were immediately lost to follow up after randomisation. In the course of treatment, there was no significant difference in the incidence of adverse events reported by 83 patients on fedotozine $(59.7 \%)$ and by 72 patients taking placebo $(58.1 \%)$. These effects were generally mild, transient, and varied. Their distribution according to body system or type of event did not vary between groups except for pain which was more frequent in the placebo group $(4.8 \%)$ than in the active treatment group $(0.7 \%)$. There were 13 withdrawals from the fedotozine group due to adverse events and nine from the placebo group. Most patients and investigators rated fedotozine safety as excellent or good, and slightly better than placebo. No evidence of any effect by

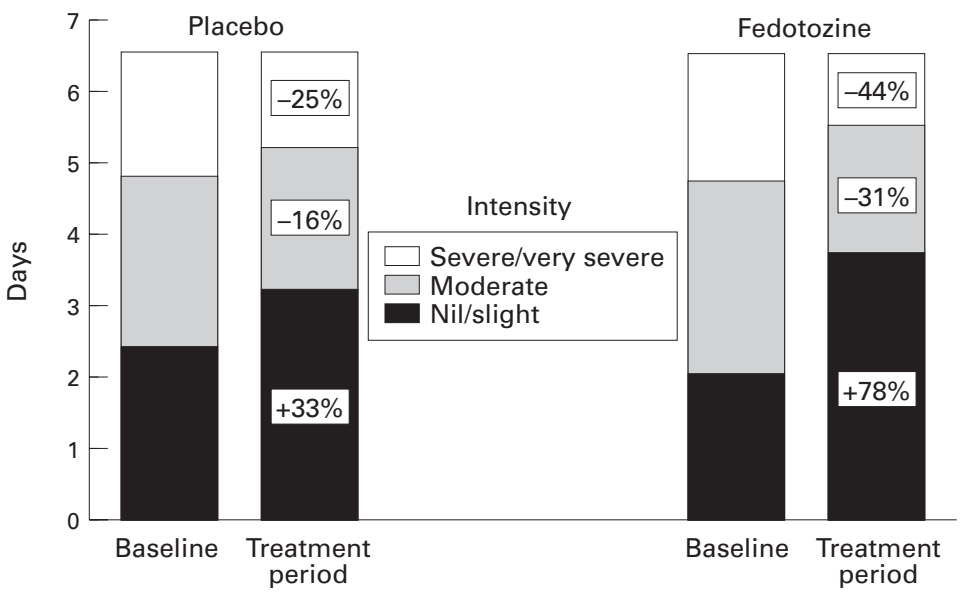

Figure 2: $\quad$ Most severe dyspeptic symptom intensity before and after treatment with placebo or $30 \mathrm{mg}$ fedotozine. Results are expressed as the percentage change in the average number of days per week at intensity levels grouped as very severe/severe, moderate, and slight/nil. fedotozine on laboratory tests was found; none of the isolated laboratory values falling outside the reference range could be related to the study treatment.

\section{Discussion}

This phase III clinical investigation of fedotozine was designed to circumvent some of the methodological limitations often encountered in dyspepsia trials. It took the form of a randomised, parallel group study which recruited its unselected dyspeptic population from both the hospital and general practice, and which measured changes in global and individual symptoms as assessed by both patients and investigators. Furthermore, the study incorporated a properly matched placebo control group, along with a placebo run in phase. The latter not only served to introduce the patients to the study protocol and provided a pretreatment baseline, but also permitted verification of compliance and proper completion of self evaluation diaries. Moreover, the investigators could ascertain that recruited patients were indeed symptomatic at randomisation. However, despite the incorporation of a placebo run in period, a placebo effect was still important during the first three weeks of active treatment as shown by repeated measurements data (fig 1).

This is the second large study comparing fedotozine with placebo in patients with functional dyspepsia. As in the previous multicentre trial, ${ }^{16}$ our results indicated that fedotozine was safe and likely to be effective in the treatment of this ubiquitous disorder. The primary efficacy criterion-patient self assessment of the overall intensity of dyspeptic symptoms - was significantly improved $(\mathrm{p}=0.002)$ by the kappa receptor agonist.

Of the individual dyspeptic symptoms, two responded particularly well to treatment: epigastric pain and nausea. The sensation of fullness was also ameliorated. The importance of the drug's ability to alleviate pain and fullness is highlighted by the fact that these symptoms were most frequently rated as being of moderate, severe, or very severe intensity at baseline, 
and considered to be the main symptoms by most patients. The patient global score, the average of the individual symptoms, was also notably improved.

Unlike the previous multicentre dyspepsia trial, the overall physician assessment of fedotozine was not statistically superior to placebo, although investigators clearly rated it as having reduced the severity of global and individual dyspeptic symptoms. This result was most likely related to the heterogeneity of efficacy scores assigned by investigators from different centres. Indeed, when evaluating changes in subjective symptoms such as those of dyspepsia, it seem more relevant to rely on the patient's assessments than those by physicians. When seen from the patient's perspective, the clinical relevance of treatment with fedotozine was demonstrated by its ability to increase slight/pain free days per week of the most severe dyspeptic symptom reported by patients by $78 \%$ versus $33 \%$ with placebo. Fedotozine also decreased the mean number of days with very severe/severe pain by $44 \%$ versus $25 \%$ with placebo (fig 2 ).

In the present study, no interaction between treatment effect and $H$ pylori status was found. Because many patients were included in the trial after endoscopy screening, $H$ pylori status was available in only about $50 \%$ of patients. In this subset, patients randomised to the fedotozine group were more often $H$ pylori positive. We have no explanation for the difference in the $H$ pylori status between the fedotozine and placebo patients.

A promising finding which emerged from this study was the distinct tendency of fedotozine to score better than placebo in the large subgroup of dyspeptic patients having associated irritable bowel symptoms. Indeed, fedotozine has proven to be effective in the relief of abdominal pain - the cardinal irritable bowel symptom. This was confirmed in a recent large double blind, dose response trial of fedotozine versus placebo in the treatment of patients with irritable bowel syndrome, in which fedotozine significantly reduced abdominal pain and bloating. ${ }^{17}$ Therefore, fedotozine appears to improve gastrointestinal sensitivity at a level of integration which may involve the entire digestive tract. The use of such kappa receptor agonists could offer a broader therapeutic option in the treatment of functional dyspepsia for which the current monovalent therapeutic approach based on symptom linked subgroup classification has not always been successful, or when irritable bowel symptoms are also present.

We gratefully acknowledge the participation of the following investigators in this study: K Bardhan, Rotherham; I Chesner, investigators in this study: K Bardhan, Rotherham; I Chesner, Birmingham; B Contractor, Thornaby; M Cottrill, Leigh; P
Evans, Titchfield; I Gilmore, Liverpool; T Harris, Bath; P HarEvans, Titchfield; I Gilmore, Liverpool; T Harris, Bath; P Har-
rison, Stockport; A Hamlyn, Dudley; P Horsfield, Blackpool; A rison, Stockport; A Hamlyn, Dudley; P Horsfield, Blackpool; A
Hungin, Eaglescliffe; R Johri, Blythe; P Keeling, Dublin; I Hungin, Eaglescliffe; R Johri, Blythe; P Keeling, Dublin; I
Kemp, Reading; P Marazzi, West Horley; J Misiewicz, London; B Pippet, Dublin; E Raubitschek, Addingham; P Smith, Southampton; C Smith, Llandough; R Valori, London; J Warren, London; P Whorwell, Manchester; and P Williams, Luton. We also express our thanks for the expert assistance provided by $\mathrm{Dr}$ B Scherrer (Institut de Recherche Jouveinal, Fresnes, France) for statistical analysis, Dr V Wills (BIOS, Bagshot, UK) for study monitoring, and Dr J Wyatt (Leeds, UK) for pathology of gastric biopsy samples.

1 Jones R, Lydeard S. Prevalence of symptoms of dyspepsia in the community. Lancet 1989 ; i: $47-51$.

2 Talley NJ, Zinsmeister AR, Schleck CD, Melton LJ III. Dyspepsia and dyspepsia subgroups. A population-based study. Gastroenterology 1992; 102: 1259-68.

3 Mearin F, Cucala M, Azpiroz F, Malagelada JR. The origin of symptoms on the brain-gut axis in functional dyspepsia. Gastroenterology 1991; 101: 999-1006.

4 Lémann M, Dederding JP, Flourié B, Franchisseur C, Rambaud JC, Jian R. Abnormal perception of visceral pain in response to gastric distension in chronic idiopathic dyspepsia: the irritable stomach syndrome. Dig Dis Sci 1991; 36: 1249-54.

5 Malagelada JR, Stanghellini V. Manometric evaluation of functional upper gut symptoms. Gastroenterology 1985; 88: 1223-31.

6 Labo G, Bortolotti M, Vezzadini P, Bonora G, Bersani G. Interdigestive gastroduodenal motility and serum motilin levels in patients with idiopathic delay in gastric emptying. Gastroenterology 1986; 90: 20-2

7 Camilleri M, Brown ML, Malagelada JR. Relationship between impaired gastric emptying and abnormal gastrointestinal motility. Gastroenterology 1986; 91: 94-9.

8 You CH, Chey WY, Lee KY, Menguy R, Bortoff A. Gastric and small intestinal myoelectric dysrhythmia associated with chronic intractable nausea and vomiting. Ann Intern Med 1981; 95: 449-51.

9 Stanghellini V, Camilleri M, Malagelada JR. Chronic idiopathic intestinal pseudo-obstruction: clinical and intestinal manometric findings. Gut 1987; 28: 5-12.

10 Talley NJ, Piper DW. The association between non-ulcer dyspepsia and other gastrointestinal disorders. Scand $\mathcal{f}$ Gastroenterol 1985; 20: 896-900.

11 Pascaud X, Honde C, Le Gallou B, et al. Effects of fedotozine on gastrointestinal motility in dogs: mechanism of action and related pharmacokinetics. F Pharm Pharmacol 1990; 42: 546-52.

12 Diop L, Rivière P, Pascaud X, Junien JL. Peripheral kappa opioid receptors mediate the antinociceptive effect of fedotozine on the duodenal pain reflex in rat. Eur $\mathcal{F}$ Pharmacol 1994; 271: 65-71.

13 Langlois A, Rivière P, Pascaud X, Diop L, Junien JL. Kappa receptors play a major role in the enhanced antinociceptive effect of fedotozine on colonic hypersensitivity in rat [abstract]. Gastroenterology 1993; 104: A538.

14 Gue M, Junien JL, Pascaud X, Bueno L. Antagonism of stress-induced motor alteration and plasma cortisol release by fedotozine (JO 1196) in dogs. F Gastrointest Motil 1990; 2: $258-64$.

15 Coffin B, Jian R, Lémann M, et al. Fedotozine increases threshold of discomfort to gastric distension in healthy subjects [abstract]. Gastroenterology 1992; 102: A437.

16 Fraitag B, Homerin M, Hecketsweiler P. Double-blind dose-response multicenter comparison of fedotozine and placebo in treatment of nonulcer dyspepsia. Dig Dis $\mathrm{Sci}$ 1994; 39: 1072-7.

17 Dapoigny M, Abitbol J-L, Fraitag B. Efficacy of the peripheral kappa agonist fedotozine versus placebo in the dose-response study. Dig Dis Sci 1995; 40: 2244-9. 